University of Nebraska - Lincoln

DigitalCommons@University of Nebraska - Lincoln

Publications, Agencies and Staff of the U.S.

Department of Commerce

U.S. Department of Commerce

7-2009

\title{
Mammal-eating killer whales and their prey-trend data for pinnipeds and sea otters in the North Pacific Ocean do not support the sequential megafaunal collapse hypothesis
}

\author{
P. R. Wade \\ Alaska Fisheries Science Center, National Marine Fisheries Service, NOAA \\ J. M. Ver Hoef \\ Alaska Fisheries Science Center, National Marine Fisheries Service, NOAA \\ D. P. Demaster \\ Alaska Fisheries Science Center, National Marine Fisheries Service, NOAA
}

Follow this and additional works at: https://digitalcommons.unl.edu/usdeptcommercepub

Part of the Environmental Sciences Commons

Wade, P. R.; Ver Hoef, J. M.; and Demaster, D. P., "Mammal-eating killer whales and their prey-trend data for pinnipeds and sea otters in the North Pacific Ocean do not support the sequential megafaunal collapse hypothesis" (2009). Publications, Agencies and Staff of the U.S. Department of Commerce. 180. https://digitalcommons.unl.edu/usdeptcommercepub/180

This Article is brought to you for free and open access by the U.S. Department of Commerce at DigitalCommons@University of Nebraska - Lincoln. It has been accepted for inclusion in Publications, Agencies and Staff of the U.S. Department of Commerce by an authorized administrator of DigitalCommons@University of Nebraska - Lincoln. 
MARINE MAMMAL SCIENCE, 25(3): 737-747 (July 2009)

This article is a US Government work and is in the public domain in the USA.

DOI: $10.1111 / \mathrm{j} .1748-7692.2009 .00282 . \mathrm{x}$

\title{
Mammal-eating killer whales and their prey-trend data for pinnipeds and sea otters in the North Pacific Ocean do not support the sequential megafaunal collapse hypothesis
}

\author{
P. R. WADE \\ J. M. VER HOEF \\ D. P. DeMaster \\ Alaska Fisheries Science Center, \\ National Marine Fisheries Service, NOAA, \\ 7600 Sand Point Way, NE, \\ Seattle, Washington 98115, U.S.A. \\ E-mail: paul.wade@noaa.gov
}

Springer et al. (2003) proposed a sequential megafauna collapse hypothesis to explain the decline of pinniped species and northern sea otters in the North Pacific. This hypothesis has been critiqued at length by DeMaster et al. (2006), Mizroch and Rice (2006), Trites et al. (2007), and Wade et al. (2007). At the core of the sequential megafauna collapse (SMC) hypothesis is the idea that predation by killer whales caused the sequential declines of four prey species (Springer et al. 2003) in the vicinity of the Aleutian Islands, Bering Sea, and Gulf of Alaska. Wade et al. (2007) plotted trends regionally and argued that the declines of pinnipeds appeared to be concurrent rather than sequential. DeMaster et al. (2006) statistically analyzed the available data and concluded that the data did not support the hypothesis that the declines of populations of northern fur seals (Callorbinus ursinus), Steller sea lions (Eumetopias jubatus), and harbor seals (Phoca vitulina) were sequential. In response, Springer et al. (2008) have fit a model similar to that used in DeMaster et al. (2006) and noted that the midpoints of the declines (the inflection points, representing the year in which $50 \%$ of the decline had occurred) are, in many cases, significantly different by their calculations. From this they conclude that the pinniped declines are sequential. The objectives of this letter are to clarify issues of statistical modeling in DeMaster et al. (2006) and Springer et al. (2008) and include further data and analyses. Springer et al. (2008) extended their work by selecting and analyzing several subseries of the Steller sea lion and sea otter (Enhydra lutris) count data. To respond to Point 2 of Springer et al. (2008), here we reanalyze subseries

Editor's Note: The Letter of response above by Wade et al. was limited by me to addressing only the new analysis presented in the Letter by Springer et al. (2008). The Letter by Estes et al. on pages 748-754 is the opportunity to rebut this response. These two Letters, which stem from responses to the original paper by Springer et al. 2003 and rebuttals to the responses will be the last Letters published in Marine Mammal Science in this string of responses. The Journal will look forward to papers that provide new data that address the hypotheses and questions raised by these various publications. 


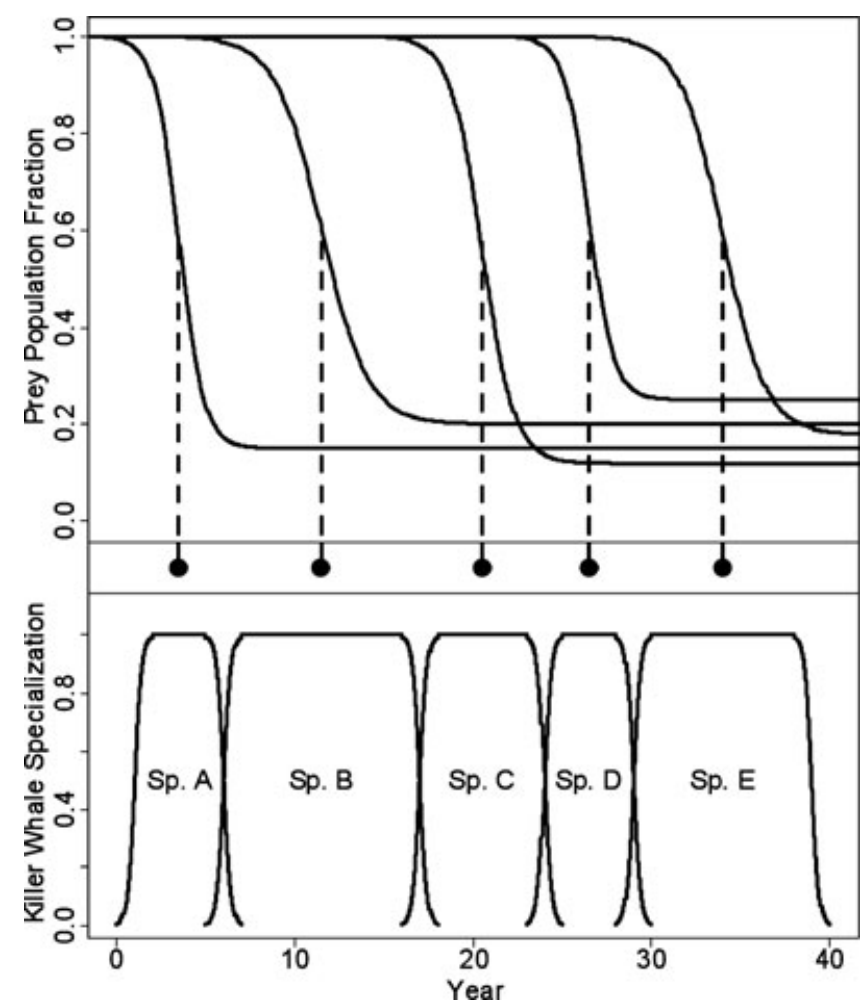

Figure 1. An idealized model of the SMC hypothesis. The lower panel shows the proportion of effort killer whales allocate to prey in a sequence of periods of specialization on species A-E. The upper panel shows a population collapse of the species being exploited, with the timing of the midpoint of decline shown by the solid circle in the middle panel.

of the same Steller sea lion and sea otter data and show that the full results are not in agreement with the SMC hypothesis; it should be noted that this letter is solely focused on the new analysis presented in Point 2 and does not discuss the other points raised by Springer et al. (2008), which were extensively discussed in DeMaster et al. (2006), Mizroch and Rice (2006), Trites et al. (2007), and Wade et al. (2007).

\section{The Analysis of DeMaster et al. (2006)}

DeMaster et al. (2006) used a Cramer-von-Mises test of whether the years of steepest decline (the midpoints of the declines) were random, clustered, or separated by a minimum number of years (a minimum interval). Springer et al. (2008) argue this is not a logical extension of their idea, but we believe it is. The heart of the disagreement can be explained using Figure 1, where the bottom panel models how killer whales specialize and then switch prey species, resulting in the decline of prey species shown in the top panel. The timings of the declines (summarized by the 
midpoints) are shown by the solid circles. For our purposes, the only data available are trends in prey species' populations, from which we try to infer whether the SMC hypothesis is valid. Statistical analyses involve fitting models to declines and then analyzing and/or interpreting the temporal pattern of the midpoints.

Part of the disagreement involves what is the appropriate null model for the temporal pattern of declines. When using the notion of parsimony, the natural null model is that all declines have the same midpoint (this is the model with the fewest parameters), which means simultaneous (clustered) declines for all prey species. Springer et al. (2008) suggest that rejection of this hypothesis supports their claim that declines are sequential, but rejection of this hypothesis only shows that the declines did not all happen at exactly the same time. The analysis in DeMaster $e t$ al. (2006) supports this statistical result as well (rejection of a simultaneous decline of whales, pinnipeds, and sea otters); however, we dispute that this provides evidence for the SMC hypothesis. Based on a model of decline midpoints, we believe that the Springer et al. (2008) use of sequential is tautological to the SMC hypothesis; if the midpoints of the decline are different, the declines are said to be sequential regardless of how close together in time they are, but if enough data are collected, all midpoints will be significantly different.

We think a better null model is one where the declines occur independently (randomly); that is, they are temporally different from each other to a greater or lesser extent (sequential in that sense), but are unrelated to each other. The SMC hypothesis links prey declines through specialization and switching by killer whales. This creates blocks of time (Fig. 1) determined by how readily killer whales can deplete the biomass of the prey that they have switched to. This block of time will vary from species to species, but there will be little advantage in specializing on a prey with very little biomass (which would be depleted very quickly). The point at the center of the decline and the minimum interval around it could be modeled as, for example, a "hard-core" process from the statistical literature on point processes (e.g., Cressie 1993, p. 669). Most noteworthy is that if the minimum interval is not very short, these types of processes will tend to be more regular than random, which explains the use of the Cramer-von-Mises test by DeMaster et al. (2006). In our case here of five species declining across an $\sim 40$-yr period, a minimum interval of $10 \mathrm{yr}$ would require a very regular pattern whereas a minimum interval of $4 \mathrm{yr}$ would allow for a more random pattern.

Of course, there is greater statistical power to detect greater effect sizes (greater minimum intervals); we conducted a simulation that shows that the analysis reported by DeMaster et al. (2006) would have a statistical power of $0.16,0.31,0.52$, and 0.80 for minimum intervals of $3,4,5$, or $6 \mathrm{yr}$, respectively, for five prey species (four intervals) over a 40-yr period using a hard-core model for simulation. Our basic premise is that detection of spacing more regular than random would support the SMC hypothesis; anything else would not (but neither would it refute the SMC hypothesis). DeMaster et al. (2006) did not find a significant result supporting a model with minimum intervals between the declines, and could not reject the null hypothesis that the declines occurred at random times. The reason for this is evident from the close proximity in time of the midpoints of the pinniped declines combined 
with the substantial gap before and after those declines. Therefore, DeMaster $e t$ al. (2006) concluded from the Cramer-von-Mises test that the data did not provide support for the SMC hypothesis, and we still hold that view.

Springer et al. (2008) also pointed out that midpoints are estimated with error, which was not considered in the Cramer-von-Mises test in DeMaster et al. (2006), nor have we discussed it yet. This is a valid point, but inclusion of such error would make the test less powerful, so the conclusion would be the same; we cannot find evidence to support the SMC hypothesis under the null model of independent declines as defined by midpoints. Alternatively, definitions based on midpoints could be abandoned and the SMC hypothesis could be better modeled based on timing and overlap of endings and beginnings of declines. This would require more complicated modeling and even more detailed data, which are unavailable, so we do not pursue that approach.

The analysis of DeMaster et al. (2006) estimated decline midpoints of 1978.5 for harbor seals, 1979.8 for northern fur seals, and 1983.3 for Steller sea lions, which has the declines of all three species occurring within 5 yr. Even if we agreed that these estimates represent these species trends throughout the region (which we do not; see further analysis below), we would argue that this would represent extremely rapid switching between prey by mammal-eating killer whales, and seems unlikely to us. It seems inconceivable that the harbor seal population would be depleted to the extent that killer whales would need to switch to northern fur seals after only $1.3 \mathrm{yr}$, and that in turn northern fur seals would be depleted after only $3.5 \mathrm{yr}$ requiring a switch by killer whales to Steller sea lions. This could only happen if these species in question had very little biomass, which does not appear to be the case; in particular, it has been pointed out that the biomass of fur seal remained high even after their decline, providing little motivation for a switch to Steller sea lions or sea otters (Wade et al. 2007). From this point alone we feel the SMC hypothesis is invalidated, but we go on to show that the declines occur at different times in different areas for some species, leading to a different sequence of declines between species, further showing there was no clear pattern of sequential declines in the pinniped species and sea otters in the northern North Pacific.

\section{ReAnalysis of TREND Data}

Here we perform a reanalysis of marine mammal trend data using identical models as those used in DeMaster et al. (2006) and Springer et al. (2008), which only differed in their specification of the variance parameter. For this parameter, DeMaster et al. (2006) assumed the variance was proportional to the mean whereas Springer $e t$ al. (2008) assumed a constant variance. Springer et al. (2008) argued that a variance proportional to the mean is a strong assumption but we argue so is the assumption of a constant variance. Rather than debate the point, we fit both models and chose the model with the smallest negative log-likelihood; because the number of parameters are equal, this is equivalent to Akaike information criterium (AIC) model selection (Burnham and Anderson 1999). 
One other assumption was required to complete the estimation of model parameters. For some of these data sets, we found the maximum population size before the decline ( $\beta_{2}$ in Springer et al. 2008) required an upper bound. It is unclear whether or how Springer et al. (2008) bounded this parameter. Choosing an upper bound of $100 \%$ is equivalent to an assumption that the population had not declined prior to the collection of data. This represents a strong assumption, given that in many of the data sets the populations appeared to be declining when data collection began. Therefore, we analyzed the data not only under this assumption, but also under a different assumption that this parameter could not be greater than four times the greatest abundance estimate. This assumption was based on inspection of the Steller sea lion data sets with the earliest data (e.g., eastern Aleutian Islands), where abundance in 1980 (when the later data sets begin) had declined to approximately 25\% of initial abundance. If the maximum abundance parameter before the decline is estimated to be greater than the first abundance estimates, this will shift the estimated midpoint back in time to an earlier year.

Finally, as in Springer et al. (2008), we checked the confidence limits by fitting a one-dimensional profile likelihood. It is not clear how Springer et al. (2008) computed confidence intervals. We found the confidence intervals estimated by profile likelihood often departed substantially from those based on Wald statistics (see Meeker and Escobar 1995, for explanation and comparisons), and from those presented in Springer et al. (2008). This can be seen in Figure 2 when the estimate (solid circle) is near the endpoint of the confidence interval, indicating a skewed profile likelihood. Therefore, we show profile likelihood confidence limits for each estimated midpoint.

Springer et al. (2008) analyzed count data of Steller sea lion rookeries from the eastern, central, and western Gulf of Alaska (GOA), but chose to ignore sea lion rookery data from the Aleutian Islands, though the decline of Steller sea lions was first detected in the eastern Aleutian Islands (Braham et al. 1980). Additionally, they grouped rookeries differently than traditionally done for trend analysis of Steller sea lions. We suggest that trend-site data are better for examining trends of Steller sea lions (e.g., Fritz et al. 2008). The trend-site data include not only the rookery counts but also include counts from haul-outs on the same surveys; Springer $e t$ al. (2008) made the point that sea lions may move between rookeries and haul-outs, and for this reason the trend-site data are preferred. For completeness, we analyzed both trend site and rookery counts for the traditional six regional groupings used for trends, including three regions in the Aleutian Islands (Fritz et al. 2008, NMFS 2008), because York et al. (1996) found through cluster analysis that these divisions grouped rookeries and haul-outs with similar trends. For our final conclusions we use only the trend-site data, and therefore for clarity we show only the trend-site data results in Figure 2B.

Springer et al. (2003) only examined sea otter data from the entire Aleutians Islands, a series that consists of data from only 3 yr. Springer et al. (2008) added a new analysis where they estimated the midpoint of sea otter trend data from Adak Island (in the central Aleutian Islands). Data from aerial surveys (five estimates from the years 1959, 1962, 1965, 1992, and 2000) are also available for two other islands 

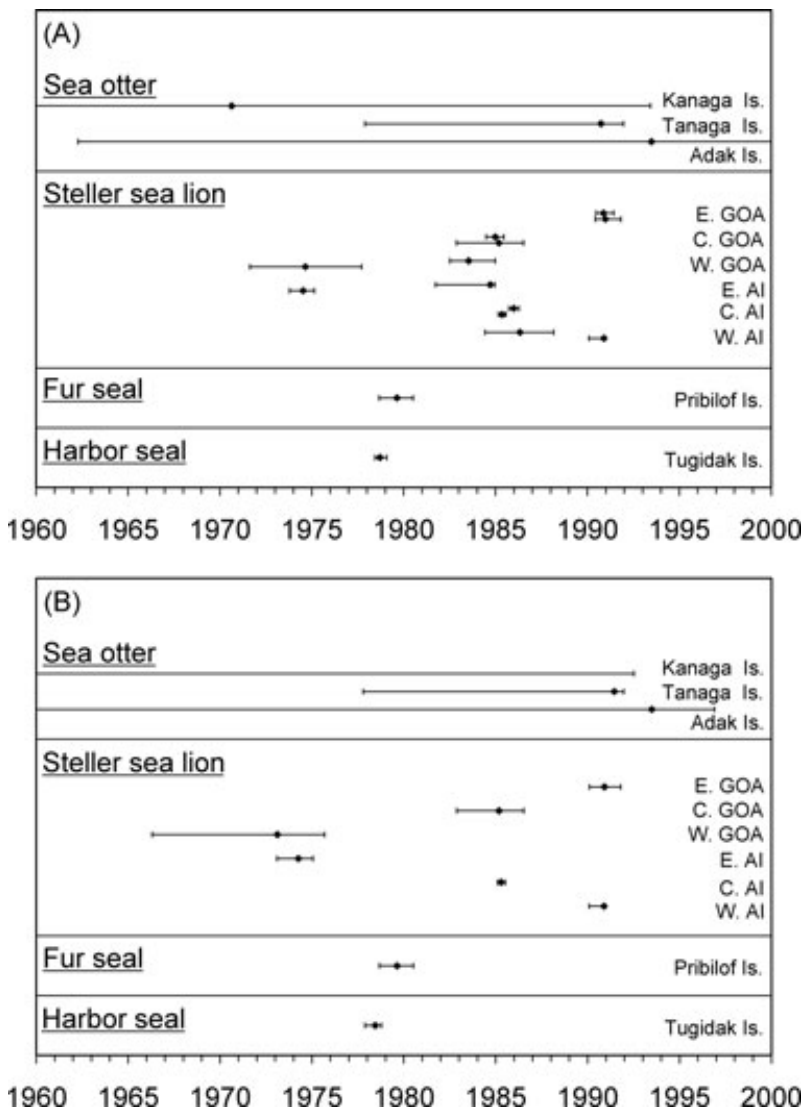

Figure 2. Maximum likelihood estimates (circles) and $95 \%$ confidence limits (lines) of the midpoints of population declines for harbor seal, northern fur seal, Steller sea lion, and sea otter. The model used was identical to that used in DeMaster et al. (2006) and Springer et al. (2008). (A) The initial population size parameter is bounded at the largest abundance estimate. (B) The initial abundance parameter is bounded at $400 \%$ of the greatest abundance estimate. Conclusions in the paper are based on results in (B) (see text for explanation). Sea otter data are from Doroff et al. (2003), and sea lion data are from the eastern, central and western Gulf of Alaska (GOA), and from the eastern, central, and western Aleutian Islands (AI) (Fritz et al. 2008). In (A) the sea lion data are plotted as pairs; the upper point in each pair represents a fit to Steller sea lion rookery data and the lower point in each pair represents a fit to Steller sea lion trend-site data (includes rookeries and haul-outs); in (B) only the trend data are plotted as they are most appropriate. The northern fur seal data include counts from both St. Paul Island and St. George Island from 1970 to 2000. The harbor seal data are from Tugidak Island from 1976 to 2003 (Jemison et al. 2006). Some lower confidence limits are off the graph.

in the central Aleutian Islands (Doroff et al. 2003), but Springer et al. (2008) did not analyze those data. Here, we analyze all three aerial survey data sets from Doroff $e t a l$. (2003), from Adak, Tanaga, and Kanaga islands. We use the same data for harbor seals (from Tugidak Island in the central Gulf of Alaska) and northern fur seals (from 
the Pribilof Islands north of the eastern Aleutian Islands) as used by DeMaster $e t$ al. (2006).

\section{Results and Conclusions From the Trend Analysis}

The model fits to the data can be viewed as supporting information online (Fig. S1-S6). Models with the variance proportional to the mean (as in DeMaster $e t$ al. 2006) were chosen by AIC 22 times and models with a constant variance were chosen 16 times; in general, the choice of variance model did not have a large influence on the estimated midpoint except for cases with very broad confidence intervals where the midpoints were estimated poorly in either case. Therefore, the choice of a variance model did not influence interpretation of the results.

Although it is clear that sea otters declined substantially in the Aleutian Islands, the data are inadequate to precisely estimate the midpoint of the declines (Fig. 2), as there is insufficient information to determine the onset of the decline. This is not an unexpected result when fitting a five-parameter model to five data points - there are no degrees of freedom left. The decline at Kanaga Island was estimated to have begun earlier (estimated midpoint of 1972 or earlier), but none of the sea otter estimates are significantly different from one another, and overlap broadly with the declines of the pinniped species.

Steller sea lions show large regional differences in the timing of their declines (Fig. 2), with estimated midpoints ranging from 1971 to 1991. In some cases where no data exist prior to the decline, the midpoints are poorly defined. In many cases the rookery count data and trend-site data show good agreement, but in other cases they show wide discrepancies even within a region. Overall, as has been noted before (Merrick et al. 1987), the declines show a pattern of beginning earlier in the middle of the range of the western stock of Steller sea lion, and occurring later at the fringes of the range (in the eastern GOA and western Aleutian Islands). Braham et al. (1980) were the first to note that a decline of Steller sea lions occurred in the eastern Aleutian Islands in the mid 1970s; we estimate the midpoint of that decline here (from trend-site data) as 1974.3 (95\% confidence limit 1973.1-1975.1; Fig. 2B).

For some populations (e.g., WGOA sea lions) our use of profile likelihood confidence showed substantial differences from results in Springer et al. (2008), as did grouping the sea lion data into the usual trend regions described by York et al. (1996) (e.g., the midpoint of the decline of the eastern Gulf of Alaska is about four years later in our results). When the assumption that no decline had occurred prior to the collection of data was relaxed, it was found that many of the data sets were inadequate for estimating the timing of the decline. From an inspection of the data, this is an obvious result-for populations that were already declining at the time data collection started the initial population size may be essentially unbounded. The point estimate and confidence limits for the midpoint were shifted to earlier years, in some cases dramatically so (Fig. 2B). This shows that the assumption of no decline prior to data collection had a strong influence on the results for at least four populations (Kanaga Island and Adak Island sea otters, WGOA, and WAI Steller sea lions). 
It is clear that no single estimate can adequately describe the timing of the decline of Steller sea lions. The assumption that populations could not have declined prior to the start of data collection seems untenable; therefore, we consider the results in Figure $2 \mathrm{~B}$ the basis for our following conclusions.

In light of the regional or area differences seen in sea otter and Steller sea lion population trends, we repeat the concern that using trends in harbor seal from one location (Tugidak Island in the central GOA) may be unrepresentative of regional trends. The data from Otter Island (three data points, see Springer et al. 2008) are inadequate for estimating the timing of a decline, so we have not plotted a midpoint for that data set. Additionally, harbor seals in Bristol Bay (Port Moller to Cinder River) are thought to have been roughly stable from 1965 to 2001 (Wade et al. 2007), and we also note that harbor seals in Nanvak Bay (in northwestern Bristol Bay) increased from 1990 to 2000 (Jemison et al. 2006). The only data set that really shows that a species declined within a broad region at a specific time is that of the northern fur seal at the Pribilof Islands, where annual or biannual counts provide a high degree of resolution that correctly reflects the regional trend, as the Pribilof Island counts represent the great majority of the fur seals in the Aleutian Islands and Bering Sea.

If we look at the major regions, in the Gulf of Alaska, we can conclude that harbor seals at Tugidak Island declined prior to Steller sea lions in the central and eastern GOA, but declined roughly concurrently with sea lions in the western GOA. Sea otters in the central and eastern GOA are not thought to have declined and have actually increased in some areas, while sea otters in the western GOA (along the Alaska Peninsula) have declined. ${ }^{1}$ Northern fur seals do not occur in the GOA in substantial numbers, so here the sequence hypothesized by Springer et al. (2003, 2008) should be harbor seals, then Steller sea lions, then sea otters; the trend data and additional information only support one of the links in that sequence-harbor seals at Tugidak Island did decline prior to Steller sea lions in the same area (central GOA) but not before Steller sea lions in the adjacent western GOA.

In the Aleutian Islands and Bering Sea region, northern fur seals declined in the middle of a period in which Steller sea lion were declining but there were large regional differences in the timing of the sea lion declines. Some of the declines of sea lions were significantly earlier than the decline of northern fur seals, and some were significantly later, while some have overlapping confidence limits. The data were inadequate to define the midpoint of the sea otter declines in the Aleutian Islands. Although we do not analyze Aleutian Islands harbor seal data here, Small et al. (2008) concluded that the number of harbor seals declined in the Aleutian Islands between 1977-1982 and 1999; when that decline began is unknown as it could have begun before or after the 1977-1982 period. Therefore, we are left with overlapping confidence limits between all four species (Fig. 2). The sequence hypothesized by Springer et al. $(2003,2008)$ should be harbor seals, then northern fur seals, then Steller sea lions, then sea otters; the trend data and additional information do not support any of the three links in that sequence-harbor seals cannot be

\footnotetext{
${ }^{1}$ USFWS draft Stock Assessment Report Southwest Alaska sea otter, 31 January 2008.
} 
shown to have declined before northern fur seals, which cannot be shown to have declined before Steller sea lions, which cannot be shown to have declined before sea otters.

In conclusion, when the analysis of Springer et al. (2008) is performed upon all appropriate data sets, with reasonable assumptions, we cannot detect a clear and simple sequence of declines of pinnipeds and sea otters from these data in either the Gulf of Alaska or the Aleutians Islands/Bering Sea region. Steller sea lions, sea otters, and probably harbor seals all show regional or area differences in the timing of their declines. The midpoint of the declines of Steller sea lions occurred over a 20-yr period depending upon location, and therefore the sequence of declines between species varies between locations. Springer et al. (2008) argue that harbor seals, Steller sea lions, and northern fur seals declined in a sequence spanning $5 \mathrm{yr}$; we show that Steller sea lions in some areas declined $7 \mathrm{yr}$ earlier or $12 \mathrm{yr}$ later than harbor seals and northern fur seals, and we argue this is evidence against the SMC hypothesis.

Whereas DeMaster et al. (2006) previously agreed that the decline of sea otters followed the decline of pinnipeds, the reanalysis and inclusion of additional sea otter data from the central Aleutian Islands suggests that the data are inconclusive. The estimated midpoints of the declines of sea otters were not significantly different from the midpoints of the declines of the pinniped species, so the trend data do not provide strong evidence that killer whales switched prey from pinnipeds to sea otters. Overall, sea otters in the central Aleutian Islands were reported to have declined by 50\% between 1965 and 1992 (Doroff et al. 2003). However, because no comprehensive survey data were collected between the surveys done in 1965 and 1992 , it is impossible to accurately estimate the beginning or midpoint of that decline.

The more carefully we examine the marine mammal trends used by Springer $e t$ al. $(2003,2008)$, the more convinced we are that those data are too sparse, especially in the early periods of declines, to give us precise answers to the questions critical to the support of the SMC hypothesis. Only one out of the five potential sequences of declines in the Gulf of Alaska and Aleutian Islands and Bering Sea is supported by the trend data. We do not believe that explanations for the decline of pinnipeds and sea otters in the North Pacific Ocean need to be restricted to the SMC hypothesis. Without a significant new body of data, there is unlikely to be statistical support for the SMC hypothesis as an explanation of pinniped and sea otter declines in the North Pacific. We recommend that further research be focused on the role mammal-eating killer whales may have played in the declines of pinnipeds and sea otters without being constrained by a belief that sequential declines caused by prey switching necessarily occurred.

\section{ACKNOWLEDGMENTS}

We thank Lowell Fritz for help with the Steller sea lion data. We thank Peter Boveng, Nancy Friday, and Tim Gerrodette for helpful reviews of this manuscript, and Gary Duker for a thorough editing of the manuscript. 


\section{Literature Cited}

Braham, H. W., R. D. Everitt and D. J. Rugh. 1980. Northern sea lion decline in the eastern Aleutian Islands. Journal of Wildlife Management 44:25-33.

Burnham, K. P., AND D. R. Anderson. 1999. Model selection and inference: A practical information-theoretic approach. Springer, New York, NY.

Cressie, N. A. C. 1993. Statistics for spatial data. Wiley and Sons, New York, NY.

DeMaster, D. P., A. W. Trites, P. J. Clapham, S. Mizroch, P. R. Wade, R. J. Small and J. Ver Hoef. 2006. The sequential megafaunal collapse hypothesis: Testing with existing data. Progress in Oceanography 68:329-342.

Doroff, A. M., J. A. Estes, M. T. Tinker, D. M. Burn and T. J. Evans. 2003. Sea otter population declines in the Aleutian archipelago. Journal of Mammalogy 84:5564.

Fritz, L., M. LynN, E. Kunisch and K. Sweeney. 2008. Aerial, ship, and land-based surveys of Steller sea lions (Eumetopias jubatus) in Alaska, June and July 2005-2007. U.S. Department of Commerce, NOAA Technical Memorandum NMFS-AFSC-183. $70 \mathrm{pp}$.

Jemison, L. A., G. W. Pendleton, C. A. Wilson and R. J. Small. 2006. Long-term trends in harbor seal numbers at Tugidak Island and Nanvak Bay, Alaska. Marine Mammal Science 22:339-360.

Meeker, W. Q., AND L. A. Escobar. 1995. Teaching about approximate confidence regions based on maximum likelihood estimation. American Statistician 49:48-53.

Merrick, R. L., T. R. Loughlin and D. G. Calkins. 1987. Decline in abundance of the northern sea lion, Eumetopias jubatus, in Alaska, 1956-86. Fishery Bulletin U.S. 85:351365.

Mizroch, S. A., AND D. W. Rice. 2006. Have North Pacific killer whales switched prey species in response to depletion of the great whale populations? Marine Ecology Progress Series 310:235-246.

NMFS (NAtional Marine Fisheries Service). 2008. Recovery plan for the Steller sea lion (Eumetopias jubatus). Revision. National Marine Fisheries Service, Silver Spring, MD. $325 \mathrm{pp}$.

Small, R. J., P. L. Boveng, V. G. Byrd and D. E. Withrow. 2008. Harbor seal population decline in the Aleutian archipelago. Marine Mammal Science 24:845-863.

Springer, A. M., J. A. Estes, G. B. Van Vliet, T. M. Williams, D. F. Doak, E. M. Danner, K. A. Forney And B. Pfister. 2003. Sequential megafaunal collapse in the North Pacific Ocean: An ongoing legacy of industrial whaling? Proceedings of the National Academy of Sciences of the United States of America 100:1222312228.

Springer, A. M., J. A. Estes, G. B. Van Vliet, T. M. Williams, D. F. Doak, E. M. DANNER AND B. Pfister. 2008. Mammal-eating killer whales, industrial whaling, and the sequential megafaunal collapse in the North Pacific Ocean: A reply to the critics of Springer et al. 2003. Marine Mammal Science 24:414-442.

Trites, A. W., V. B. Deeke, E. J. Gregr, J. K. B. Ford and P. F. Olesiuk. 2007. Killer whales, whaling, and sequential megafaunal collapse in the North $\mathrm{Pa}$ cific: A comparative analysis of the dynamics of marine mammals in Alaska and British Columbia following commercial whaling. Marine Mammal Science 23:751765.

Wade, P. R., V. N. Burkanov, M. E. Dahlheim, N. A. Friday, L. W. Fritz, T. R. Loughlin, S. A. Mizroch, M. M. Muto, D. W. Rice, L. G. Barrett-Lennard, N. A. Black, A. M. Burdin, J. Calambokidis, S. Cerchio, J. K. B. Ford, J. K. Jacobsen, C. O. Matkin, D. R. Matkin, A. V. Mehta, R. J. Small, J. M. Straley, S. M. Mccluskey, G. R. VAn Blaricom and P. J. Clapham. 2007. Killer whales and marine mammal trends in the North Pacific - a re-examination of evidence for sequential megafauna collapse and the prey-switching hypothesis. Marine Mammal Science 23:766802. 
York, A. E., R. L. Merrick and T. R. Loughlin. 1996. An analysis of the Steller sea lion metapopulation in Alaska. Pages 259-292 in D. R. McCullough, ed. Metapopulations and wildlife conservation. Island Press, Washington, DC.

Received: 15 July 2008

Accepted: 11 November 2008

\section{SUPPORTING INFORMATION}

Additional Supporting Information may be found in the online version of this article:

Figure S1. Stellar sea lion fits using $100 \%$ as the maximum for the fitted model. The solid line is the fit using the model where the variance is linearly related to the mean, and the dashed line is the fit with the constant-variance model. An "-R" designation refers to rookery-only data, and a "-T" designation refers to trend-site data (rookeries and haul-outs). See main paper for a full description.

Figure S2. Stellar sea lion fits using $400 \%$ as the maximum for the fitted model. The solid line is the fit using the model where the variance is linearly related to the mean, and the dashed line is the fit with the constant-variance model. An "- $\mathrm{R}$ " designation refers to rookery-only data, and a "- $T$ " designation refers to trend-site data (rookeries and haul-outs). See main paper for a full description.

Figure S3. Sea otter fits using $100 \%$ as the maximum for the fitted model. The solid line is the fit using the model where the variance is linearly related to the mean, and the dashed line is the fit with the constant-variance model.

Figure S4. Sea otter fits using $400 \%$ as the maximum for the fitted model. The solid line is the fit using the model where the variance is linearly related to the mean, and the dashed line is the fit with the constant-variance model.

Figure S5. Harbor seal and fur seal fits using $100 \%$ as the maximum for the fitted model. The solid line is the fit using the model where the variance is linearly related to the mean, and the dashed line is the fit with the constant-variance model.

Figure S6. Harbor seal and fur seal fits using $400 \%$ as the maximum for the fitted model. The solid line is the fit using the model where the variance is linearly related to the mean, and the dashed line is the fit with the constant-variance model. 